\title{
Una práctica experimental con la arcilla en favor del proceso creativo infantil.
}

\author{
TIPO DE TRABAJO \\ Comunicacion virtual. \\ PALABRAS CLAVE \\ Arcilla, niños y niñas, proceso creativo, educación artística.
}

\section{KEY WORDS}

Clay, children, creative process, artistic education.

\section{RESUMEN}

En busca de ampliar el marco de actuación de la arcilla en un contexto contemporáneo para su utilización en el ámbito infantil, se propone un espacio de reflexión y proyección que permita expandir las posibilidades plástico- expresivas de este medio material para potenciar el desarrollo de la expresión, creatividad y experiencia artística del niño y de la niña.

Para llevarse a cabo, primeramente se realiza una investigación bibliográfica en torno a prácticas y autores relacionados al área de la arcilla, con autores como V. Lowenfeld, A. Stern, L. Kampmann o B. Munari, entre otros, que se complementa con la elaboración de un cuestionario a personas escultoras ceramistas, A. Mujika, V. Frois, M. Díaz o C. Spaggiari que por su experiencia personal y profesional valoran el barro como una herramienta con gran potencial didáctico y artístico.

Y por otro, unas prácticas experimentales, con niños y niñas de 6 a 8 años de edad para tener una primera toma de contacto con el medio, permitiendo observar y analizar in situ su modo de relación con este medio material y reflexionar sobre los factores que intervienen en el desarrollo de su proceso creativo.

La arcilla como elemento material en relación a la Educación Artística tiene un papel importante para construir un saber interdisciplinar con base en la exploración sensorial, el conocimiento directo del entorno y la capacidad de transformación a través de la proyección personal y del contacto corporal con el medio para la expresión y creación del niño y la niña, sobre todo en épocas donde desde muy pequeños se crece junto a tecnologías táctiles de comunicación y manipulación de la realidad.

\section{ABSTRACT}

The aim of this research is to extend the clay's frameworks for action in a contemporary context for its later use in children. Thus, this paper proposes a space of reflection and projection that allows to expand the plastic and expressive possibilities of this material and, therefore, to enhance child's expressivity development, creativity and artistic experience.

For this purpose, a literature review around the use and practice of clay has been done first, leading to some authors, such as V.Lowenfeld, A.Stern, L. Kampmann or Bruno Munari, among others. Then, the research has been complemented with a questionnaire to a certain number of sculptor ceramists (A. Mujika, V.Frois, M. Díaz or C. Spaggiari) who appreciate the value of clay as a tool with great didactic and artistic potential, due to their own personal and professional experience 
Secondly, the paper shows some experimental practices with 6 to 8 years old children that had their first contact with the clay environment. These practices allowed us to observe and analyze in situ how was their relationship with this material and to reflect on the factors that are involved in the development of their creative process.

Clay has long been recognized as an important part of a well-rounded Artistic Education because of its interdisciplinary knowledge based on a sensory exploration, direct knowledge of environment and the ability to transform children's creativity through personal projection and body contact with the material. This is especially important when it comes to screen time, tactile communication technologies and manipulation of reality.

\section{CONTENIDO}

\section{Introducción}

Esta propuesta surge como fundamento teórico práctico para la realización del Trabajo Fin de Máster de Cerámica, Arte y Función de la Universidad del País Vasco UPV/EHU, titulado "La utilización de la arcilla como medio material para el desarrollo del proceso creativo infantil: Propuesta de una práctica experimental", tutorizado por Juan Ruiz Gómez.

Debido a mi trayectoria trabajando como educadora plástica con niños /as de 4 a 12 años de edad desde hace varios años en el ámbito de la plástica de la enseñanza no formal, llevo analizando las problemáticas en torno a la utilización del barro y otras disciplinas artísticas dentro del mundo infantil en centros escolares o en otros de carácter no formal y se puede observar como en muchas ocasiones resulta poco frecuente o incluso poco significativas el tipo de actividades que se ofertan a los niños/as, y que en ocasiones no brindan herrramientas adecuadas para ayudar al niño/a a proyectarse a lo largo de su proceso evolutivo.

Por otro lado, es importante señalar a la hora de buscar fuentes bibliográficas o documentos sobre prácticas artísticas relacionadas con la utilización de la arcilla en el campo infantil, la falta de publicaciones e información al respecto. En general, existe mayor material publicado sobre la pintura y el dibujo, encontrando una escasez en el desarrollo del barro e incluso en el ámbito de lo tridimensional, el volumen y conceptos como el espacio.

Al realizar el máster, me pareció interesante aprovechar ese espacio educativo y artístico, un espacio de artistas y educadores, para reflexionar y proyectar nuevas perspectivas de la arcilla, para mi a título personal y por consecuencia para futuros proyectos educativos en los que quiero trabajar. El ponerme en contacto con personas escultoras, ceramistas y profesoras a la vez ofrece la oportunidad de intercambiar modos de elaborar proyectos educativos en favor de los niños/as y el barro, desde la propia experiencia artística de cada uno/a, ya que muchos de ellos en sus inicios desarrollaron proyectos artísticos con gran potencial didáctico.

Así nace la idea de crear un espacio en que los niños/as y el barro sean los protagonistas, en el que se puedan ampliar las posibilidades plastico-expresivas del barro para el desarrollo del proceso creativo infantil donde la aproximación al medio ofrezca actividades adecuadas a los niños /as para favorecer su expresión, su creatividad y su experiencia artística.

\section{La utilización de la arcilla en el ámbito infantil}

A modo de contextualización, se indaga sobre la existencia de metodologías o actividades relacionadas con la arcilla y los niños/as, como fuente de información que extienda el lugar que ocupa en la sociedad, para plantear nuevas propuestas que permitan crecer e incorporarlas al mundo infantil.

Se realiza una búsqueda documental sobre autores/as que hayan trabajado en este ámbito. Entre ellos /as se podrían destacar :

V. Lowenfeld, 1903-1960 psicólogo y profesor de Educación artística en la Universidad Estatal de Pensilvania, Estados Unidos en su libro Educación Creadora, propone la utilización de la arcilla como complemento al desarrollo de la educación creadora con la actividad artística. "la arcilla es muy importante ya que ofrece la oportunidad de manipular un material tridimensional que puede ser apretado, estirado, comprimido y machacado." (Lowenfeld y Lambert, 1970:131)

"El sacar trozos de arcilla del total, o reunir partes ya realizadas no es simplemente un medio superficial de lograr la forma, sino que es algo que está íntimamente arraigado en el pensamiento del niño"(1970:219) 
A.Stern, 1924, investigador y profesor alemán, desarrolla una educación creativa a través de la pintura. En su proceso de investigación en torno a la expresión creativa, realizó una práctica de la arcilla con niños /as mediante el modelado, en la que propone el mundo de las tres dimensiones como complemento al desarrollo de un conjunto de técnicas para la Educación artística, para "el enriquecimiento de los medios de expresión del niño con miras de evolución."(Stern, 1964:1)

Partiendo de la necesidades del niño/a, plantea que el educando se reencuentre con sus deseos y formas de exploración para ayudarlo a desarrollarse mediante la enseñanza de la técnica.

Bruno Munari, 1907-1998, diseñador, poeta, escultor, pedagogo, propone una metodología que desarrolla a través de laboratorios con niños/as de diferentes edade, en la que utiliza las bases de la pedagogía activa, "Giocare con l'arte", laboratorio vinculado a la cerámica que fue propuesto en el Museo Internacional de la Cerámica de Faenza en 1979, que sigue vigente hasta la actualidad.

Construye espacios para desarrollar la creatividad, el conocimiento, la experimentación, el descubrimiento y el autoaprendizaje, favoreciendo un pensamiento creativo del niño/a.

L. Kampmann, 1925-1993.Escultor y pintor alemán, profesor del departamento de arte y enseñanza de la Universidad Pedagógica de Dortmund, Alemania.

En uno de sus libros publicados, "Modelar y dar forma" realiza una propuesta sobre el tratamiento del modelado con diferentes materiales plásticos, plastilina, arena, cera, pasta de papel y arcilla para trabajar con los niños/as, señala la importancia del acto de modelar en el niño/a, dado que ayuda a trabajar aspectos relevantes para su aprendizaje.

"Por medio del sentido del tacto nuestras relaciones y nuestras experiencias con los objetos de nuestro mundo son a menudo intensas puesto que se trata del contacto más directo. Para modelar hace falta: tomar, tocar, amasar y, al mismo tiempo, observar, pensar, controlar. (...) El contacto directo de las manos con un material plástico sirve para dirigirlas y educarlas. La mano se sensibiliza y pasa de la simple manipulación inconsciente al modelado razonado."(Kampmann,1969:5)

Paralelamente a la búsqueda sobre documentación publicada se propone la puesta en contacto con otras personas cercanas al ámbito infantil y la arcilla para intercambiar y conocer distintos planteamientos de artistas que están en continuo proceso de creación y que por su conocimiento del medio, valoran el potencial para su desarrollo como herramienta educativa, y que gracias a su colaboración han compartido su trabajo, a pesar de que muchas no estén publicadas oficialmente en libros.

Para ello se plantea la realización de un cuestionario que permita la recopilación de proyectos por un lado, para observar y analizar las metodologías que se utilizan, sus contextos, sus contenido y por otro lado, una serie de preguntas para reflexionar sobre el valor artístico y educativo de este material en favor del desarrollo del proceso creativo del niño/a.

Se podrían destacar los nombres de algunas de las participantes:

Marilia Diaz, ceramista y profesora de la Universidad Federal de Paraná, Brasil. Realiza un mural colectivo de piezas modeladas en arcilla con la colaboración de 1200 participantes de la comunidad escolar, desarrollado dentro del proyecto "El arte en la escuela" que tiene como temática "El arte registra la historia".

Virginia Frois, escultora, profesora, animadora cultural, Portugal. Primeramente desarrolló su trabajo de enseñanza en la "Oficina da crianza", taller del niño/a en el ámbito de la enseñanza no formal, en Montemor-o-Novo, Portugal. Actualmente realiza asesoramiento externo de los talleres, y se puede destacar el trabajo tutorizado de Oto Hudec, artista eslovaco, titulado "El archipiélago" llevado a cabo en Cabo Verde, en la escuela de primaria de Tras os Montes, en el ámbito de arte participativo en comunidades y minorías de diferentes partes del mundo.

Ane Mujika, profesora de Escultura, Bellas Artes UPV/EHU, País Vasco. Realizó un proyecto llamado Busti - Txuri- Lur en Zarautz, Gipuzkoa, con niños /as de 6 a 11 años de distintos centros escolares. El objetivo era dar herramientas para una metodología precisa en el mundo de la plástica., con base metodológica del laboratorio Giocare con el arte de B. Munari.

Carla Spaggiari, psicopedagoga, psicomotricista italiana se interesa por el desarrollo de la educación artística como medio de comunicación. Elabora un proyecto didáctico en el Museo de Escultura de Antón de Candas, Asturias, con la participación de dos colegios públicos, con 700 niños, 2013, en el que trabajan el retrato con el modelado en arcilla. 


\section{La arcilla}

Es un material que por sus características físicas y químicas está en continuo movimiento y transformación mediante el agua, el aire, el fuego y con nuestras manos, conectándonos con la naturaleza y el entorno.

Este medio material ha sido utilizado a lo largo de la historia, elaborando objetos utilitarios, y desde hace tiempo puede hallarse en ámbitos artísticos contemporáneos utilizándose como lenguaje artístico, donde se pueden encontrar obras realizadas en arcilla cruda o arcilla cocida, de artistas como Pere Noguera, G.Penone, V.Nascimento, etc.

Los diferentes estados matéricos en los que se presenta la arcilla seca, líquida y plástica, lo constituyen como medio adecuado para poder experimentar y explorar distintas percepciones sensoriales, construir con el medio y expresar significados.

La hipótesis de este trabajo plantea a la arcilla como un medio material en favor del desarrollo del proceso creativo infantil, debido a los diferentes canales de percepción que se establecen con la manipulación del barro, de forma lúdica y cercana y por sus variadas posibilidades matéricas de experimentación, conocimiento y construcción que proporciona de forma bidimensional y tridimensional, convirtiéndolo en un recurso adecuado para crear herramientas que potencien e impulsen un aprendizaje en favor del desarrollo de la creatividad y la evolución del niño/a. Un proceso que le facilitará ir descubriendo y estableciendo de forma paulatina y adecuada a su etapa evolutiva, un conjunto de conocimientos que le permitiran explorar y expresar su mundo imaginario.
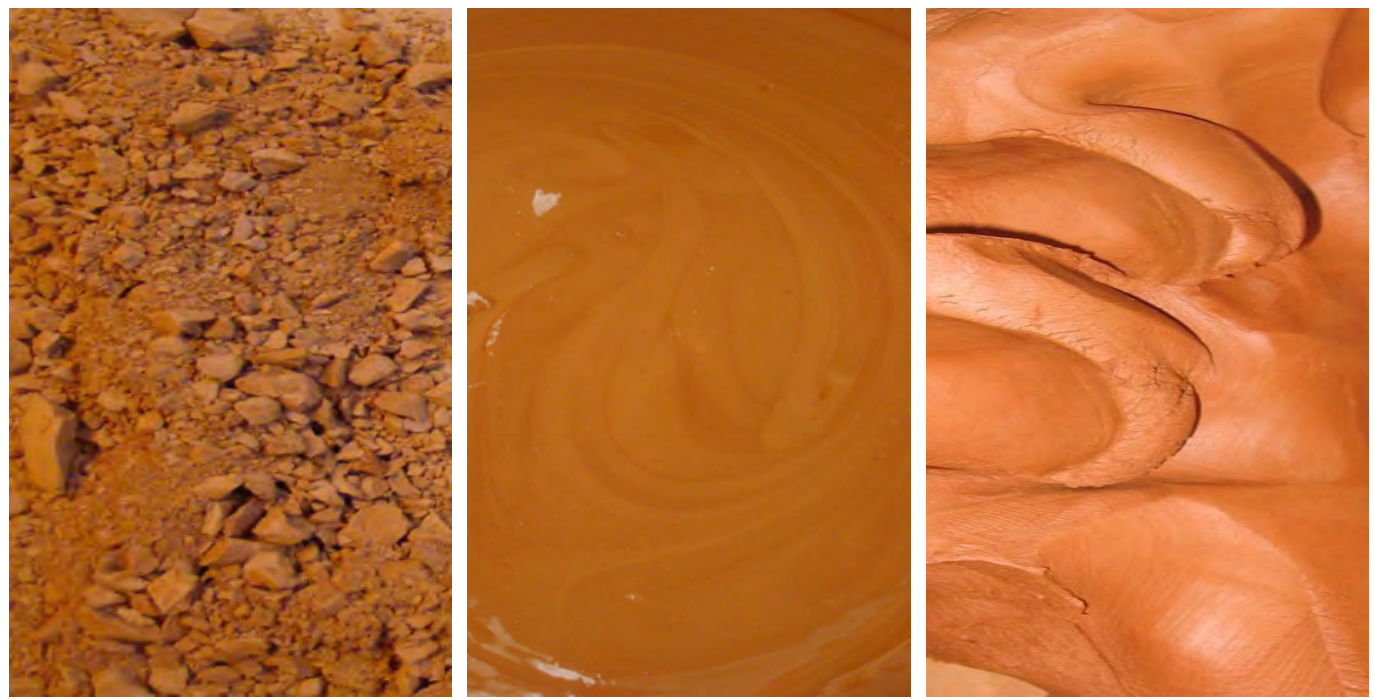

Ilustración 1. Estados de la arcilla 


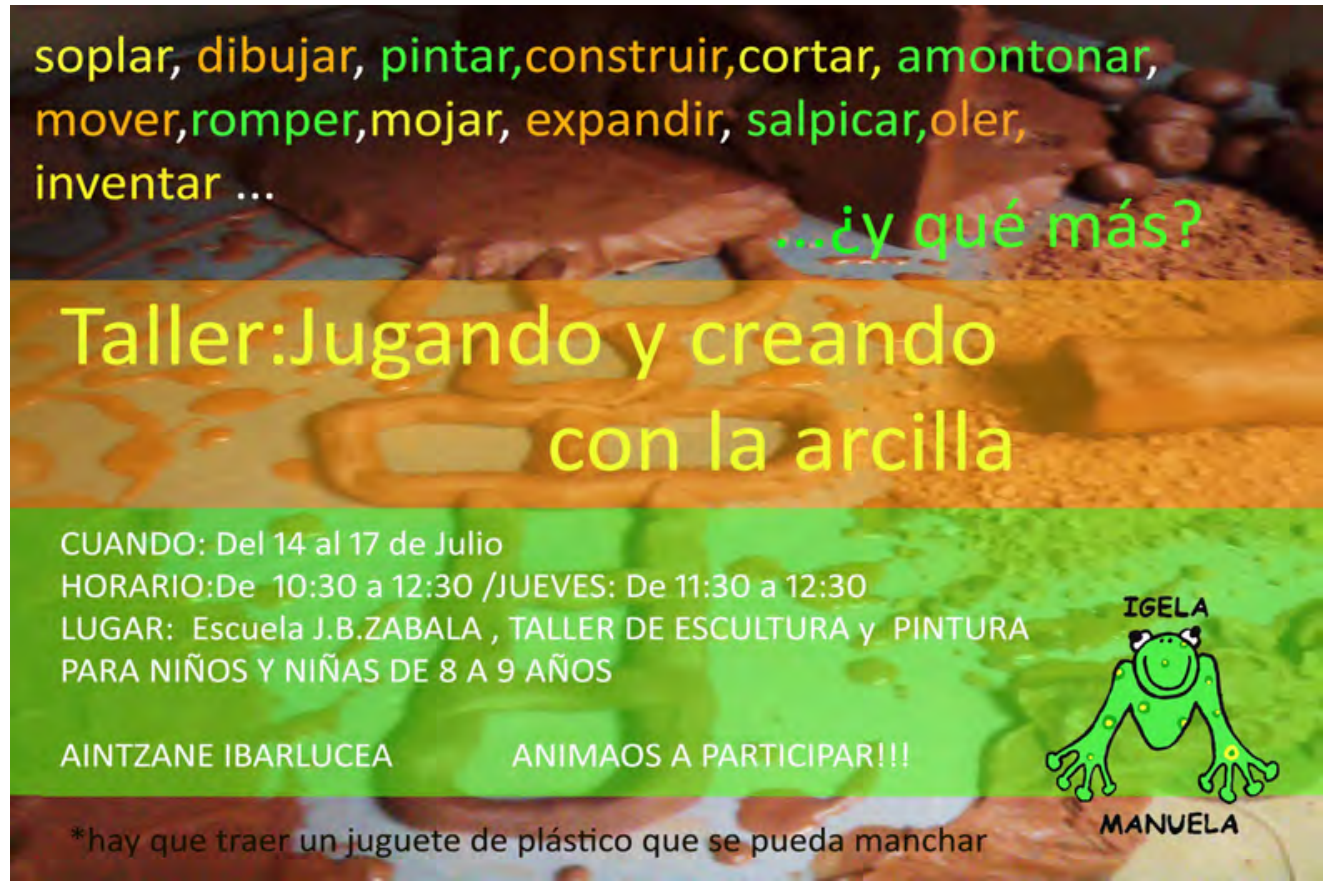

\section{Ilustración 2. Cartel de la práctica experimental}

Dado el conjunto de características matéricas que presenta la arcilla, se propone la realización de una práctica experimental para observar y analizar in situ sus formas de exploración y transformación de la materia, para reconocer el modo en que el niño/a se relaciona con la arcilla y reflexionar sobre los factores que intervienen en el desarrollo de su proceso creativo.

Esta actividad fue realizada en euskera, en C.E.P. Juan Baurista Zabala de Algorta, Bizkaia, gracias a la colaboración de la Asociación de Padres y Madres del centro y también a la Asociación Cultural Igela Manuela.

Las prácticas se desarrollaron durante tres sesiones de dos horas cada una y una última sesión de una hora de duración. El tiempo de realización se estableció de acuerdo al desarrollo de la actividad para acercar el medio al niño/a y realizar una primera toma de contacto.

La primera sesión se presentó con un bloque dirigido a LA EXPLORACIÓN Y EXPERIMENTACIÓN DEL MEDIO, en sus tres estados matéricos, para que el niño/a conozca y descubra las cualidades plásticas del material activamente mediante la realización de acciones que fueron identificando y clasificando de acuerdo a su estado matérico.

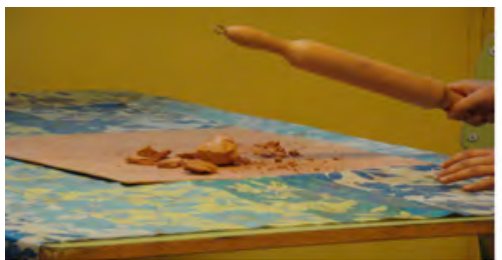

romper

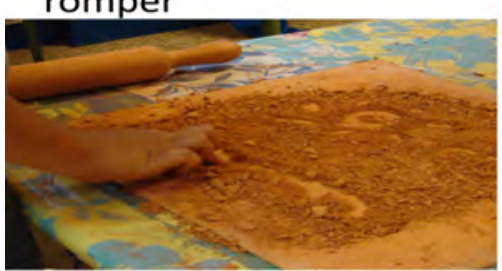

dibujar con el dedo

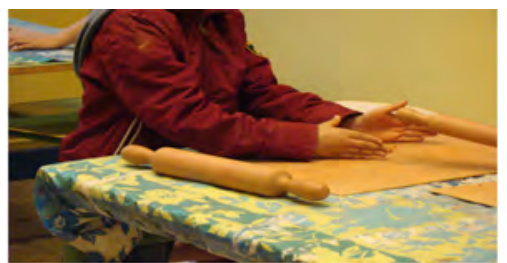

juntar, amontonar

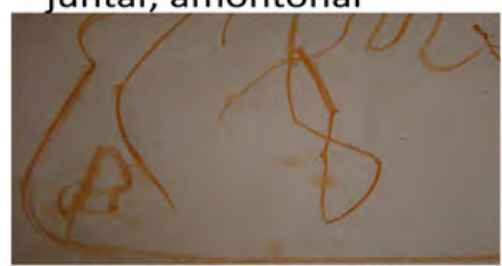

dibujar con la arcilla

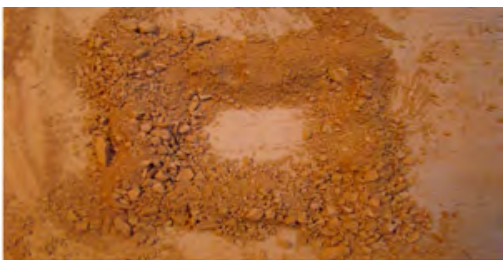

hacer montañas

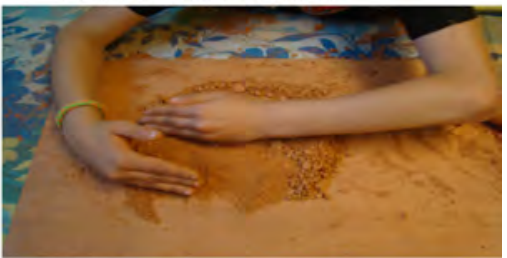

borrar

Ilustración 3. Acciones en arcilla seca 
"Su necesidad de explorar el mundo circundante para descubrir las propiedades de los objetos y de las sustancias le revelan la resistencia , la maleabilidad, la textura y las reacciones al tacto" (Stern,1964:5)

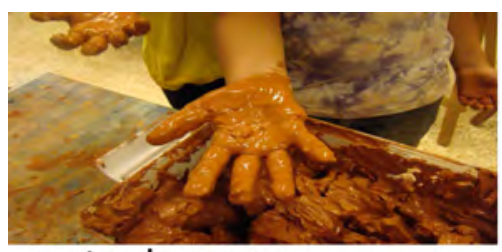

meter la mano

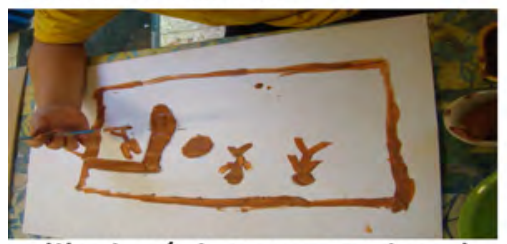

dibujar/pintar con pincel

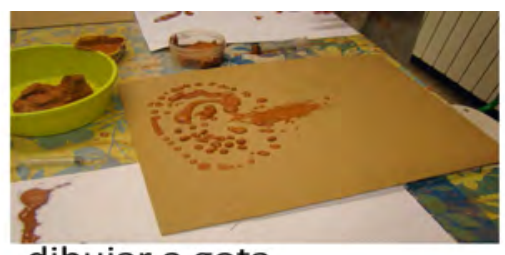

dibujar a gota

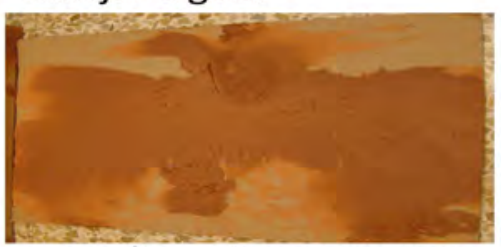

expandir y pintar con mano

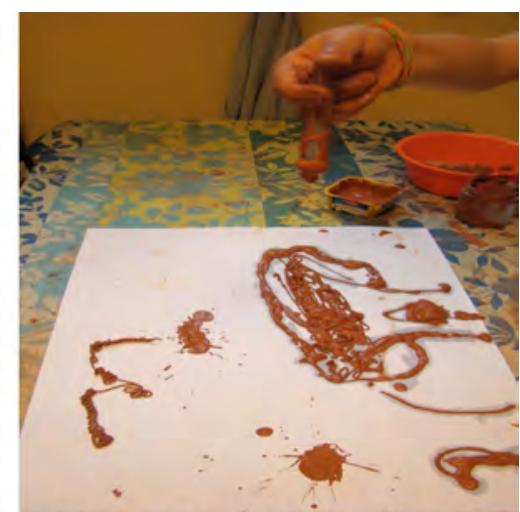

dibujar con jeringuilla a chorro

\section{Ilustración 4. Acciones en arcilla líquida}

A través de una manipulación directa de la materia, el niño/a va ampliando la calidad de su percepción del entorno mediante la conexión directa de sus manos, favoreciendo el desarrollo de la percepción táctil. Y en la medida que construye y da forma a lo que ha descubierto va estableciendo una conexión entre su mano, su mirada y el medio material. Así fueron descubriendo que con el barro pueden machacar, apretar, dar forma, dibujar, etc.
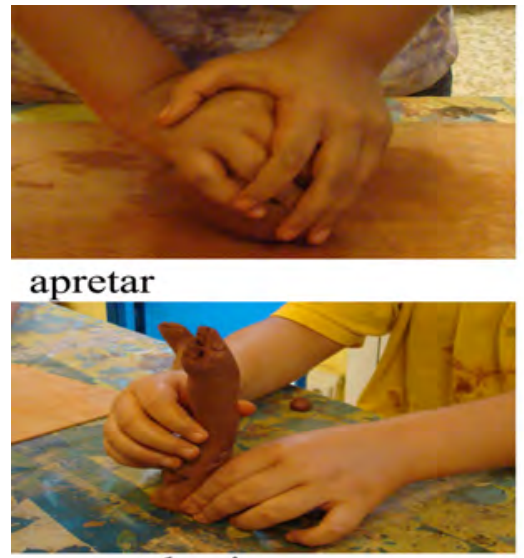

poner de pie
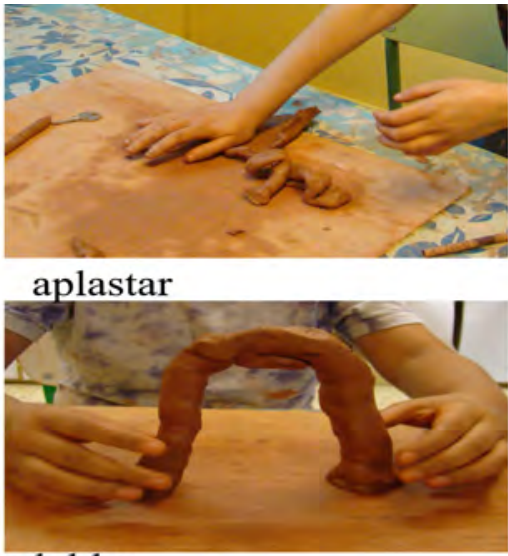

doblar
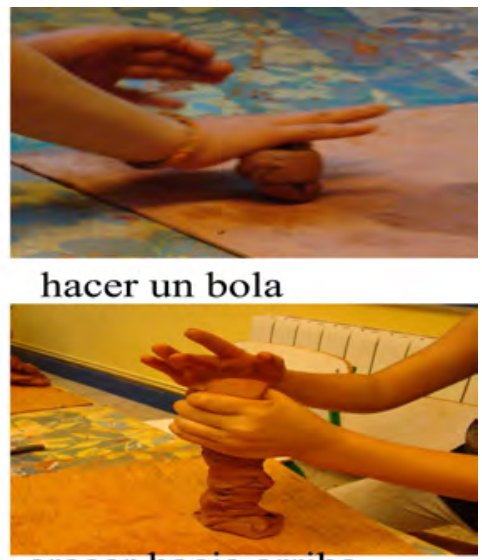

crecer hacia arriba

Ilustración 5. Acciones en arcilla plástica (pasta)

En la segunda y tercera sesión, CONSTRUCCIÓN DE UN ESPACIO Y OBJETOS ESPECIALES, debieron incorporar las acciones descubiertas el día anterior para la construcción de un espacio especial en el que la temática a tratar se basaba en un lugar singular donde puedan guardar los tesoros, secretos, juguetes y objetos importantes para ellos/as.

Se creó una motivación, que generara interés y ganas de jugar con el medio, para establecer un vínculo cercano, permitiéndoles proyectarse con su imaginación, para poder unir y transformar sus experiencias vividas impulsando la creación de imágenes visuales expresivas, nuevas y significativas para ellos.

"El edificio erigido por la fantasía puede representar algo completamente nuevo, no existente en la experiencia del hombre ni semejante a ningún otro objeto real; pero al recibir forma nueva, al tomar nueva encarnación material, esta imagen cristalizada, convertida en objeto, empieza a existir realmente en el mundo y a influir sobre los demás objetos."(Vigoskii,1999:24) 
Debido a la relación que se pretendía que los niños/as establecieran con el espacio, esta práctica fue realizada con niños/as de 8 a 9 años de edad. Según Piaget, en esta etapa espacial y evolutiva, entre los 6- 8 años y 8- 10 años que denomina nivel topológico y proyectivo, se da la representación del espacio, la consolidación entre las formas realizadas en el plano y las formas en vertical, así como las acciones temporales se transcriben en volúmnes que tienen movimiento. El niño/a comienza a fundar relaciones con el entorno que lo rodea, se une con el mundo circundante, partiendo de su experiencia corporal para relacionar los objetos, comienza a representar el lugar en donde se encuentra, descubriendo el sentido del espacio y el volumen.

Para impulsar este desarrollo espacial, el lugar de tesoros se presentó para que fuese construido dentro de una caja de cartón blanca, $33 \mathrm{x}$ 56 x $41 \mathrm{~cm}$, como si de cualquier otro soporte para la creación se tratase. Así los niños/as se encontraron con un trozo de espacio para ser intervenido con los diferentes estados del barro, que previamente estaba delimitado por paredes, suelo, techo, en el que para crear más privacidad, podían incluir parte de su cabeza y tronco para trabajar en su interior. De esta manera, tuvieron la posibilidad de crear su propio espacio, deciendo cómo iba a ser, que objetos iba a contener, incentivando en todo momento su poder de decisión en cuanto a sus deseos e ideas, de manera que no se formaran barreras para su expresión y su proceso creativo.

Comenzaron realizando dibujos o pintando los planos con barbotina, transformando la materia plástica en relieves que colgaban de las paredes, estableciendo una relación del espacio con trabajos bidimensionales hasta llegar a la construcción tridimensional de objetos que fueron relacionando entre sí para la ocupación de su espacio.
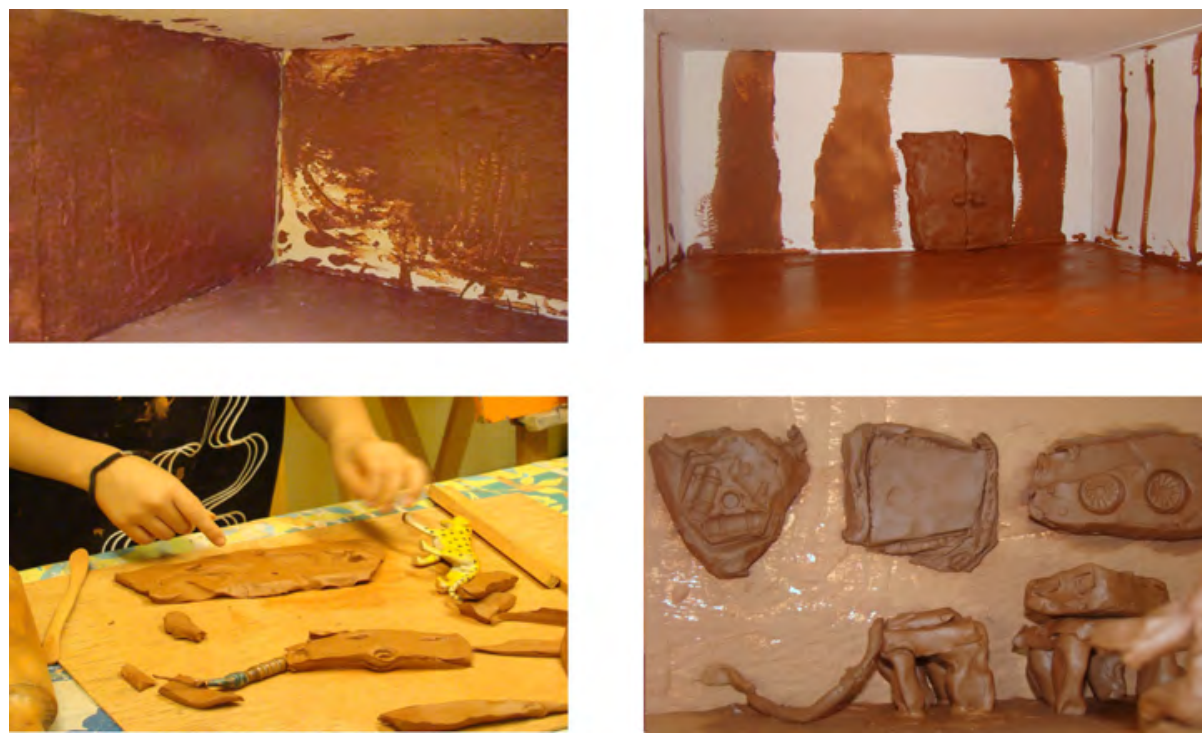

Ilustración 6. Ejemplos de la evolución de los trabajos

El barro al ser un material tridimensional, que ocupa un lugar en el espacio, por su altura, anchura y profundidad permite que el niño/a explore, manipule y transforme el material, desarrollando un amplitud de conocimientos y habilidades mediante sus manos, y su deseo de expresión, con su mirada, extendiendo su sensibilidad de la percepción visual y táctil.

Incluso establece un vínculo de la realidad de forma cercana, ya que todo lo que existe en el entorno, se encuentra en el espacio de forma tridimensional, como es el caso de su cuerpo.

"Para los niños es natural relacionar las formas con el espacio real, razón por lo que la organización espacial en la tercera dimensión supone una afirmación de su percepción real del mundo... para ellos, transferir la realidad a tres dimensiones es, en cierta manera, poseer la vida imitarla y abstraerla para apropiarse de ella."(Fosati,2000:10) 
Éstos son algunos de los resultados:

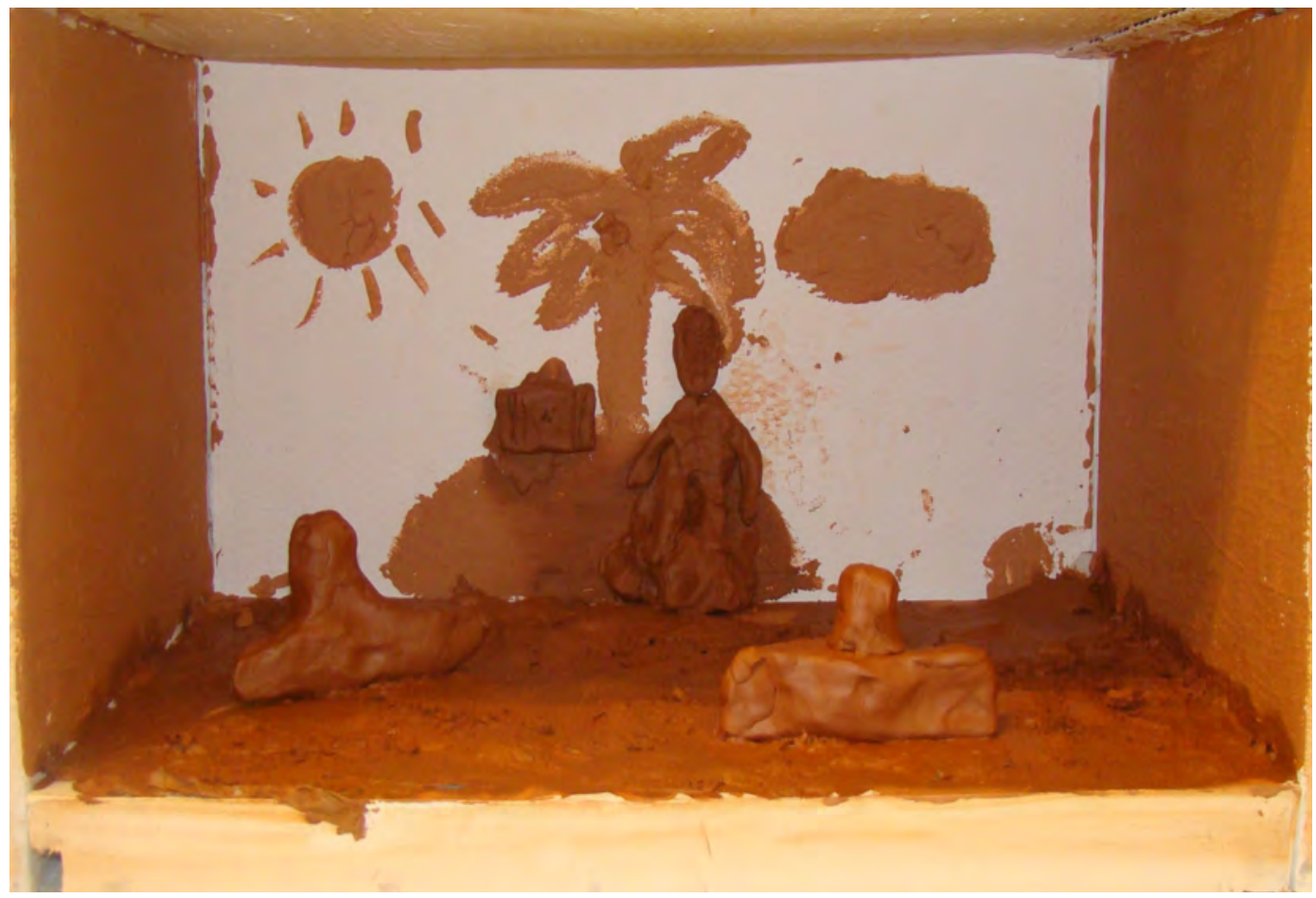

Ilustración 7. Trabajo realizado por Unai Ortiz, 8 años, titulado “Kutxa pirata/Caja pirata”

Los espacios fueron construidos como pequeños ambientes escenográficos, donde a cada niño/a, de alguna manera le gustaría estar con sus objetos especiales.

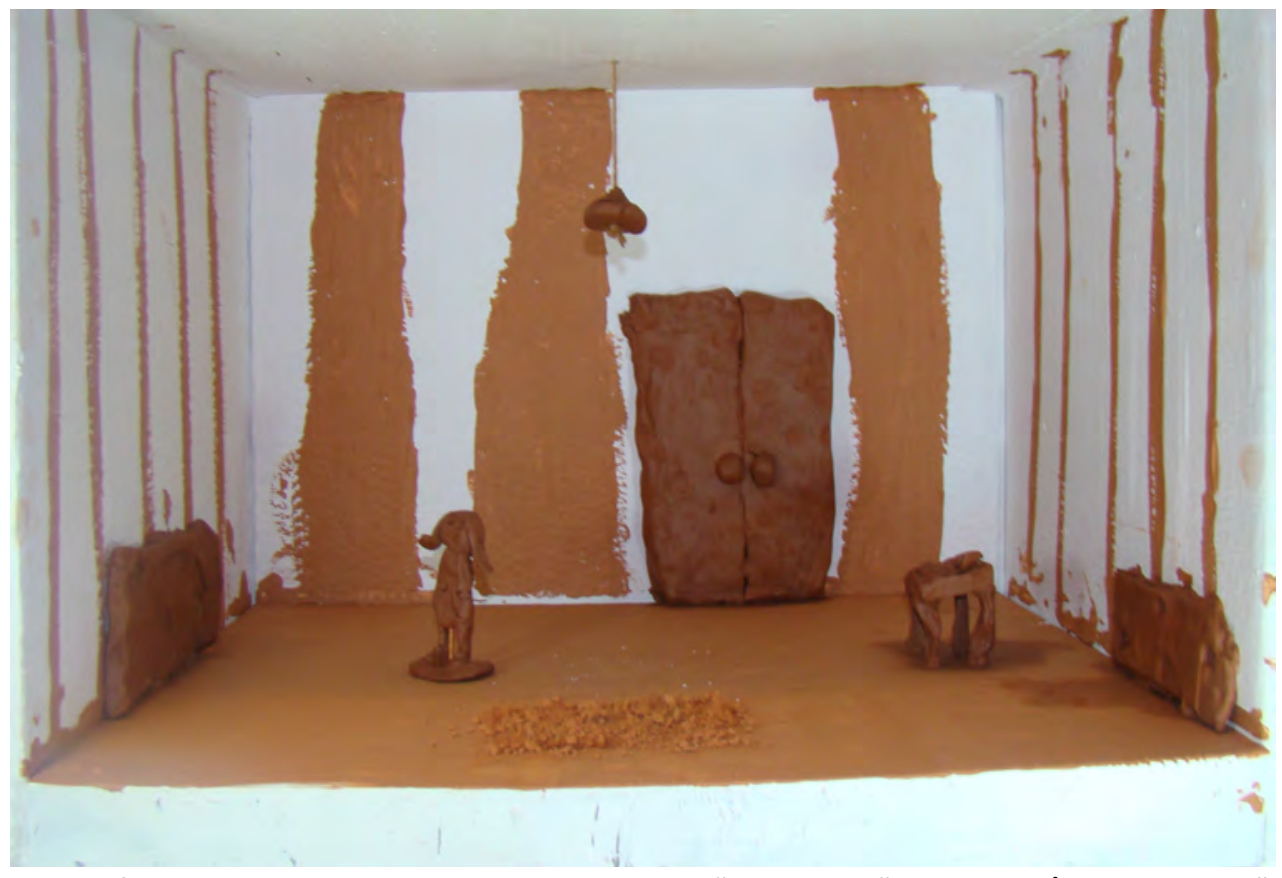

Ilustración 8. Trabajo realizado por Itxaso Susaeta, 8 años, titulado“Altxor kutxa/Caja de tesoros”. 
Tuvieron la posibilidad de conformar sus imágenes visuales, con sus deseos creando figuras para expresarse y comunicarse con el mundo exterior, desde su propia visión y búsqueda personal permitiendo la construcción de su mundo imaginario lleno de valiosos y nuevos elementos significativos para ellos/as .

"El arte puede considerarse un proceso continuo de desenvolvimiento de la capacidad creadora, puesto que todo niño trabaja - en su nivelpara producir nuevas formas menores para adaptar el tema a superficies bi y tridimensionales."(Lowenfeld y Lambert,1970:52)

Para finalizar se creó un espacio de exposición y reflexión, para crear un ambiente que permitiera analizar y valorar la actividad realizada desde la observación de los mismos. Paralelamente, se presentó de cada trabajo,estableciendo un diálogo de acuerdo a lo que cada niño/a había creado y para finalizar se abrió la exposición al público, donde los niños /as fueron los/as protagonistas, respondiendo a las preguntas que iban surgiendo de manera espontánea por parte de los espectadores/as. Esta última actividad fue aceptada de manera extraordinaria, el realizar exposiciones en las que los niños/as participan de manera activa, se convierte en algo indispensable para que se sientan valorados/as y aceptados /as por su entorno, sus compañeros/as, su familia y por ellos mismos/as, así como para saber el significado que adquirió la actividad para ellos/as.

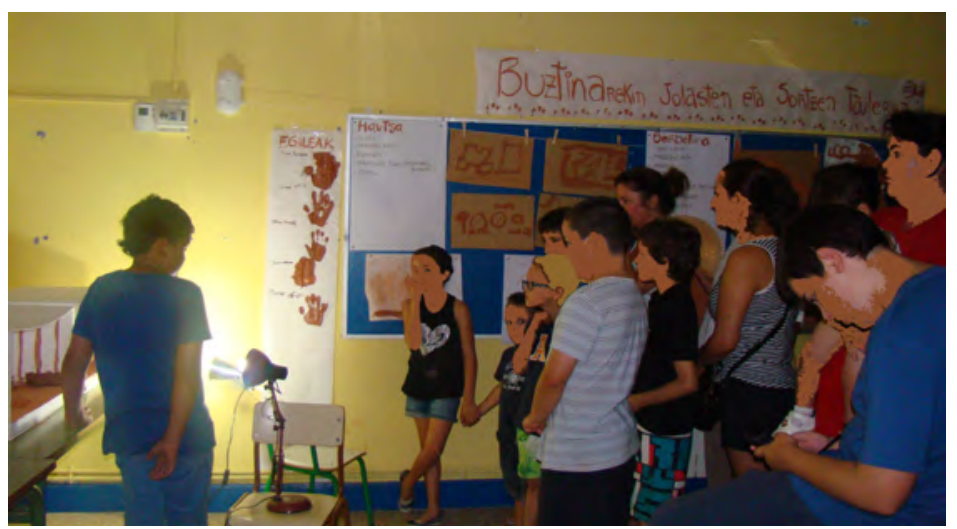

Ilustración 9. Presentación y exposición de los trabajos

\section{Conclusiones}

Si bien las prácticas experimentales se programaron para un período de corta duración y trabajar un acercamiento al medio para el niño/a, es necesario destacar, que fue una primera toma de contacto, y que debido a los resultados obtenidos se observa que hay muchas posibilidades que pueden ayudar a potenciar y desarrollar una segunda parte de este proyecto, programando actividades que comprendan al niño/a y al material en su totalidad ya que el fin de este trabajo es seguir profundizando y elaborando propuestas en futuros programas educativos.

Por otro lado, es importante considerar que la utilización de la arcilla con los niños/as elaborando actividades artísticas significativas al no ser un ámbito muy extendido es necesario conocer, dialogar y crear redes de comunicación con personas que actuan en este marco desde su propia experiencia artística. Esta indagación permite generar reflexiones en torno a problemáticas, perspectivas, experiencias , y proyectos que se convierten en aportaciones en favor del desarrollo de este medio material con nuevas espectactivas de actuación para prolongar y ampliar futuros programas artístico- educativos., Así como también es vital potenciar la participación de los artistas en entornos escolares para sensibilizar a los niños/as y al profesorado con las diferentes disciplinas artísticas y acercar la accesibilidad del arte como medio para el conocimiento y expresión del ser humano.

\section{FUENTES REFERENCIALES}

AA.VV. La educación visual y plástica hoy. Educar la mirada, la mano y el pensamiento. Grao. Barcelona. 2001.

AA.VV. Encuentros del arte, con la antropología, la psicología y la pedagogía. Angle Editorial. Barcelona. 1997.

AGIRRE, I. Teorías y prácticas en educación artística. Ideas para una revisión pragmatista de la experiencia estética. Universidad pública de 
Navarra. Pamplona. 2000.

ARNHEIM, R. Consideraciones sobre la educación artística. Ediciones Paidós. España. 1993.

BRUGUERA, J. Manual práctico de cerámica. Ediciones Omega. Barcelona. 1986.

DONDIS, D. A. La sintaxis de la imagen. Introducción al alfabeto visual. Editorial Gustavo Gili. S. A. Barcelona. 1985.

EISNER, W. Educar la visión artística. Paidós. Barcelona. 1972.

KAMPMANN,L.. Modelar y dar forma. Ediciones Bouret. París.1969.

LOWENFELD, V. y LAMBERT, N. Desarrollo de la capacidad creadora. Editorial Kapelusz. Argentina.1970.

LURIA, A. R. Sensación y percepción. Brevarios de conducta humana №6. Editorial Fontanella. Barcelona.1981.

MARÍN, R y DE LA TORRE, S. Manual de la creatividad. Aplicaciones educativas. Vicens Vives. Barcelona. 2003.

MONTAGU, A. El sentido del tacto. Comunicación humana a través de la piel. Colección Aurion. Madrid.1981.

MUSEO INTERNAZIONALE DELLE CERAMICHE FAENZA. Laboratorio Giocare con I'arte. Cuaderno 4. Faenza. Italia. 1986.

POWEL , T. El educador y la creatividad del niño. Narcea S.A. Ediciones Madrid. 1972

READ, H. Educación por el arte. Ediciones Paidós. España.1982.

STERN, A. La conquista de la tercera dimensión. Editorial Kapelusz. Buenos Aires. Argentina. 1964.

VIGOSKII, L. S. La imaginación y arte en la infancia. Akal Bolsillo. Madrid.1990.

Revistas, artículos y publicaciones

CARPINTERO, M.E. El espacio, el volumen. El volumen y el espacio. Aula de Innovación Educativa. Número 88. Página 21. Barcelona. 2000.

FOSATI PARREÑO, A. ¿Qué entendemos por volumen?Reflexiones sobre el volumen y el espacio en educación primaria. Aula de Innovación Educativa. Número 88. Barcelona. 2000.

MARTínEZ LICERANZU, J. A. Una aproximación a la enseñanza del volumen. Aula de Innovación Educativa. Número 88. Página 13. Barcelona. 2000.

MARTINEZ, E. DELGADO, J. La arcilla en el aula. Cuadernos de Pedagogía Número167. Página17. Barcelona. 1989.

ROSER JUANOLA Y TERRADELAS. Arte, ciencia y creatividad: un estudio de la escuela operativa italiana. Artículo Arte, individuo y sociedad, №9. Universidad Complutense de Madrid. 1997.

SEGURADO CORTÉS, B. VALERO CUENCA, B. El volumen: un juego en la educación infantil. Aula de Innovación Educativa. Número 88. Página 8. Barcelona. 2000.

Vallvél, LL. La exploración del espacio en la educación infantil. Aula de Innovación Educativa. Número 88. Página 17. Barcelona. 2000.

VIERA, C. Disertación. Desenvolverse no barro. A contribuiçâo das aulas de cerâmica às crianças do ensinho fundamental II. Programa de mestrado em gestào e pràticas educacionais de Universidade de Nove de Julho. PROGEPE/UNINOVE. Sao Pablo. Brasil. 2014. 